\title{
EFEITO DO BENEFICIAMENTO E APLICAÇÃO DE TRATAMENTO TÉRMICO NA COMPOSIÇÃO QUÍMICA E DIGESTIBILIDADE PROTEICA DO ARROZ
}

\author{
T. A. BECKER-ALGERI ${ }^{1}$, G. L. MENDES ${ }^{2}$, R. COLLI ${ }^{1}$, B. C. GRILO ${ }^{1}$, E. B. FURLONG ${ }^{1}$ \\ ${ }^{1}$ Universidade Federal do Rio Grande \\ ${ }^{2}$ Universidade Federal de Pelotas \\ E-mail para contato: taniabecker86@yahoo.com.br
}

\begin{abstract}
RESUMO - O arroz tem alto valor nutricional em função de sua composição química, que está diretamente relacionada com o tipo de arroz, sendo os componentes divididos nas diferentes frações do cereal. Quando é submetido a beneficiamento, alguns nutrientes podem ser separados, parcial ou inteiramente, alterando assim suas características químicas e nutricionais. O objetivo deste trabalho foi verificar a influência do beneficiamento industrial e dos tratamentos hidrotérmicos (cozimento) na composição química e digestibilidade in vitro de amostras de arroz. Para tanto, nove amostras de arroz branco, parboilizado e integral comercializados na cidade de Rio Grande - RS, foram submetidas à análise de umidade, cinzas, proteína, lipídios e digestibilidade in vitro antes e após cocção (simulação de cozimento doméstico). Os resultados indicam que quanto ao beneficiamento, as amostras de arroz integral apresentam maior teor de cinzas e lipídeos, enquanto que os demais componentes não diferiram estatisticamente entre os tipos de amostra. Após aplicação do tratamento térmico, a digestibilidade proteica aumentou consideravelmente (em torno de 50\%) indicando que o cozimento possibilitou a entrada de água entre as cadeias facilitando assim a ação das enzimas proteolíticas, aumentado consequentemente a digestilidade proteica das amostras.
\end{abstract}

Palavras-chave: cocção, digestão, proteína.

DOI: $10.5965 / 24473650312017005$

\section{INTRODUÇÃO}

O arroz (Oryza sativa L.) está entre os principais grãos cultivados no mundo e desempenha papel importante como alimento básico da população mundial. É um cereal consumido principalmente como grão inteiro e constituído por amido, proteína, lipídios, minerais e vitaminas (VIEIRA, CARVALHO, 1999). Entretanto, ao ser separado em frações durante o beneficiamento, a composição de cada uma delas é diferenciada e afetada por variáveis abióticas do ambiente, de manejo, de processamento e de armazenamento (ZHOU et al., 2002), além de variáveis bióticas que resultam em grãos com características nutricionais diferenciadas, dependendo da fração em que estão. As camadas externas apresentam maiores concentrações de proteínas, lipídios, fibra, minerais e vitaminas, enquanto o centro é rico em amido. A variação nas etapas de beneficiamento, para 
produção dos diversos tipos de arroz disponíveis para consumo, resultam, além de diferenças nutricionais, em alterações na digestibilidade proteica destes produtos, uma vez que, o teor de digestibilidade de um tecido vegetal pode ser medido através da porcentagem das proteínas que são hidrolisadas pelas enzimas digestivas e absorvidas pelo organismo na forma de aminoácidos ou de qualquer outro composto nitrogenado absorvível nas condições do trato digestório, sendo portanto, um determinante da qualidade proteica da dieta (CINTRA et al., 2007; MARCHINI et al., 1994). A forma mais usual de consumo é o endosperma amiláceo cujo polimento resulta em redução no teor de nutrientes, exceto de amido, originando as diferenças na composição entre o arroz integral, o polido e o parboilizado (STORCK, 2004). Após este tratamento, o arroz ainda é submetido a tratamento hidrotérmico (cozimento com adição de condimentos) para posterior consumo. Considerando a forma de consumo, este trabalho teve como objetivo estudar a disponibilidade e digestilidade dos nutrientes tanto na amostra in natura quanto nesta submetida aos devidos tratamentos de beneficiamento (polimento, parboilização) e para consumo (tempero, cocção e outros) realizando para tanto a caracterização nutricional através da composição química e digestibilidade proteica de arroz cru e tratado termicamente.

\section{MATERIAL E MÉTODOS}

\subsection{Amostras}

Foram coletados três diferentes tipos de arroz, classificados, de acordo com Instrução Normativa da ANVISA (BRASIL, 2009) como: arroz branco (grupo beneficiado, subgrupo polido, classe longo, Tipo I), arroz parboilizado (grupo beneficiado, subgrupo parboilizado polido, classe longo, Tipo I) e arroz integral (grupo beneficiado, subgrupo integral, classe longo, Tipo I), totalizando 9 amostras de quatro diferentes marcas. A coleta das amostras foi realizada no comércio local da cidade de Rio Grande, localizada na região sul do Rio Grande do Sul. A unidade amostral foi constituída por embalagens originais fechadas contendo, no mínimo $500 \mathrm{~g}$ de amostra, tomando-se $10 \%$ do volume total do produto disponível para venda, para comporem a amostra bruta.

Após identificação, as amostras foram homogeneizadas, através da mistura dos lotes para cada tipo de arroz, e submetidas à quarteamento manual. As amostras quarteadas foram acondicionadas em recipientes plásticos e distintamente identificadas como: amostras moídas (numeração $+\mathrm{M}$ ) e inteiras (numeração $+\mathrm{I}$ ), sendo que as inteiras foram mantidas em seu estado original, para posterior aplicação de tratamento térmico, e as amostras identificadas como moídas (M) submetidas à moagem em moinho de facas e peneiradas em peneiras de 35 mesh, para comporem a unidade amostral in natura.

\subsection{Tratamento térmico}

As amostras destinadas ao tratamento térmico foram preparadas a partir das seguintes condições para cocção: $10 \mathrm{~g}$ de amostra, $0,1 \mathrm{~g}$ de $\mathrm{NaCl}, 0,2 \mathrm{~g}$ de óleo de soja comercial e $30 \mathrm{~mL}$ de $\mathrm{H}_{2} \mathrm{O}$ destilada. Após homogeneização foram submetidas a aquecimento em chapa elétrica, a temperatura aproximada de $100{ }^{\circ} \mathrm{C}$ por $10 \mathrm{~min}$, ou até total evaporação da água residual do cozimento. Após cocção, as amostras foram submetidas à maceração em grau de porcelana, até obtenção de pasta sem presença de grãos inteiros, seguido de procedimento de preparo para 
determinação de composição química e digestibilidade proteica.

\subsection{Análises de composição química}

A composição química foi realizada por meio da determinação do teor de umidade, cinzas, proteína bruta e extrato etéreo, seguindo os métodos recomendados e descritos pela "Association of Official Analytical Chemist International" - AOAC (2000). A umidade foi determinada empregando o método gravimétrico de secagem em estufa a $105^{\circ} \mathrm{C}$, segundo o método $\mathrm{n}^{\circ} 935.29$ da AOAC (2000). A determinação de cinzas foi realizada por método gravimétrico através de incineração das amostras em forno mufla a $560{ }^{\circ} \mathrm{C}$, até obtenção de cinzas claras, conforme método $\mathrm{n}^{\circ} 923.03$ da AOAC (2000). O teor de lipídios foi determinado pela extração com solvente éter de petróleo de acordo com o método 920.85 da AOAC (2000). Os níveis protéicos foram determinados pelo método de micro-kjeldahl, $\mathrm{n}^{\circ} 920.87$ da AOAC (2000), empregando fator de conversão para proteínas de 5,95 .

\subsection{Análises de digestibilidade in vitro}

A digestibilidade in vitro das amostras foi determinada segundo adaptações do método descrito por Sgarbieri, (1996). As amostras foram submetidas à hidrólise enzimática empregando primeiramente pepsina $\left(1,5 \mathrm{mg} \mathrm{mL}^{-1} \mathrm{em} \mathrm{HCl} 0,1 \mathrm{M}\right)$ (atividade específica $18,3 \mu \mathrm{g}$ tir/min.mg prot. ${ }^{-1}$ ) por 3 horas, e posteriormente pancreatina $\left(22,5 \mathrm{mg} \mathrm{mL}^{-1}\right.$ em tampão fosfato $\mathrm{pH} \mathrm{8,0)} \mathrm{(atividade}$ específica $2,3 \mu \mathrm{g}$ tir/min.mg prot. ${ }^{-1}$ ) por 24 horas em agitador orbital a $37^{\circ} \mathrm{C}$. A hidrólise foi interrompida com adição de ácido tricloroacético seguindo-se a separação do resíduo não digerido por centrifugação $\left(3000 \mathrm{~g} / 15 \mathrm{~min} / 20^{\circ} \mathrm{C}\right)$. Os peptídeos e aminoácidos liberados foram quantificados pelo método de Folin-Ciocalteau e calculados a partir da curva padrão de tirosina $\left(0,01\right.$ a $\left.0,1 \mathrm{mg} \mathrm{mL}^{-1}\right)$ (LOWRY, et al., 1951).

\subsection{Análise estatística}

A análise estatística dos resultados obtidos foi realizada utilizando o software Statistica v. 7.0. Foram avaliadas as médias dos experimentos realizados em triplicata, e a significância de suas diferenças, empregando o teste de Tukey ao nível de confiança de $95 \%$.

\section{RESULTADOS E DISCUSSÃO}

A Tabela 01 apresenta os resultados da composição química das amostras de arroz cru e após cocção (procedimento similar ao cozimento caseiro), juntamente com o CV\% e a significâncias estatísticas das diferenças encontradas. 
Tabela 01: Composição química de amostras de arroz cru e com cocção.

\begin{tabular}{|c|c|c|c|c|c|}
\hline \multicolumn{2}{|c|}{ Amostra } & $\begin{array}{c}\text { Umidade } \\
/ \mathrm{CV} \\
\left(\mathrm{g.100g}^{-1}\right) \\
\end{array}$ & $\begin{array}{c}\text { Cinzas /CV** } \\
\left(\mathrm{g.100g}^{-1}\right)\end{array}$ & $\begin{array}{l}\text { Proteína/CV** } \\
\quad\left(\mathrm{g}^{*} 100 \mathrm{~g}^{-1}\right)\end{array}$ & $\begin{array}{c}\text { Lipídeos/CV** } \\
\left({\left.\mathrm{g} .100 \mathrm{~g}^{-1}\right)}^{2}\right.\end{array}$ \\
\hline \multicolumn{6}{|c|}{ Arroz in natura } \\
\hline Branco & 01 & $11,8^{b^{*}} \pm 3,2$ & $0,40^{\mathrm{d}} \pm 3,8$ & $8,0^{\mathrm{a}} \pm 11,4$ & $0,51^{\mathrm{c}} \pm 15,6$ \\
\hline Branco & 02 & $11,4^{\mathrm{ab}} \pm 4,0$ & $0,53^{\text {cde }} \pm 20,0$ & $8,3^{\mathrm{a}} \pm 5,9$ & $1,2^{\mathrm{a}} \pm 13,7$ \\
\hline Branco & 03 & $11,8^{\mathrm{b}} \pm 4,2$ & $0,46^{\mathrm{cd}} \pm 4,2$ & $8,5^{\mathrm{a}} \pm 10,9$ & $0,3^{\mathrm{c}} \pm 8,2$ \\
\hline Parboilizado & 04 & $10,7^{\mathrm{ab}} \pm 7,6$ & $0,56^{\mathrm{ce}} \pm 17,6$ & $6,6^{\mathrm{a}} \pm 1,9$ & $0,4^{\mathrm{c}} \pm 7,2$ \\
\hline Parboilizado & 05 & $11,4^{\mathrm{ab}} \pm 3,9$ & $0,66^{\mathrm{e}} \pm 5,8$ & $8,8^{\mathrm{a}} \pm 12,9$ & $0,4^{\mathrm{c}} \pm 13,6$ \\
\hline Parboilizado & 06 & $9,8^{\mathrm{a}} \pm 8,4$ & $0,70^{\mathrm{e}} \pm 9,1$ & $6,8^{a} \pm 12,5$ & $0,5^{\mathrm{c}} \pm 8,4$ \\
\hline Integral & 07 & $10,7^{\mathrm{ab}} \pm 2,3$ & $1,6^{\mathrm{b}} \pm 1,9$ & $7,5^{\mathrm{a}} \pm 12,8$ & $3,4^{\mathrm{b}} \pm 7,0$ \\
\hline Integral & 08 & $9,9^{\mathrm{ab}} \pm 2,4$ & $1,5^{\mathrm{b}} \pm 10,8$ & $7,9^{\mathrm{a}} \pm 5,9$ & $3,0^{\mathrm{b}} \pm 3,0$ \\
\hline Integral & 09 & $10,2^{\mathrm{ab}} \pm 5,7$ & $1,8^{\mathrm{a}} \pm 11,3$ & $7,3^{\mathrm{a}} \pm 1,3$ & $3,2^{b} \pm 2,3$ \\
\hline \multicolumn{6}{|c|}{ Arroz com cocção } \\
\hline Branco & 01 & $68,0^{c} \pm 1,8$ & $1,4^{\mathrm{c}} \pm 6,8$ & $8,6^{\mathrm{a}} \pm 7,8$ & $0,84^{\mathrm{d}} \pm 3,2$ \\
\hline Branco & 02 & $67,8^{c} \pm 1,9$ & $1,8^{\mathrm{c}} \pm 9,1$ & $8,6^{a} \pm 2,7$ & $1,3^{\mathrm{cd}} \pm 7,9$ \\
\hline Branco & 03 & $65,2^{\mathrm{bc}} \pm 5,4$ & $2,2^{\mathrm{c}} \pm 19,9$ & $7,0^{\mathrm{a}} \pm 13,5$ & $1,1^{\mathrm{cd}} \pm 18,5$ \\
\hline Parboilizado & 04 & $67,1^{\mathrm{c}} \pm 2,3$ & $1,9^{\mathrm{c}} \pm 2,1$ & $8,1^{\mathrm{a}} \pm 9,8$ & $0,5^{\mathrm{d}} \pm 14,8$ \\
\hline Parboilizado & 05 & $65,0^{\mathrm{bc}} \pm 1,3$ & $2,4^{\mathrm{bc}} \pm 6,9$ & $9,0^{\mathrm{a}} \pm 20,0$ & $1,0^{\mathrm{d}} \pm 20,1$ \\
\hline Parboilizado & 06 & $65,6^{\mathrm{bc}} \pm 0,7$ & $2,5^{b c} \pm 2,9$ & $8,4^{\mathrm{a}} \pm 9,2$ & $2,2^{\mathrm{ab}} \pm 1,6$ \\
\hline Integral & 07 & $57,2^{a} \pm 4,5$ & $4,0^{\mathrm{a}} \pm 12,7$ & $8,0^{\mathrm{a}} \pm 13,2$ & $1,5^{\mathrm{ac}} \pm 2,7$ \\
\hline Integral & 08 & $59,4^{\mathrm{ab}} \pm 4,3$ & $3,9^{\mathrm{a}} \pm 13,0$ & $6,3^{\mathrm{a}} \pm 3$ & $2,3^{b} \pm 16,3$ \\
\hline Integral & 09 & $58,9^{\mathrm{ab}} \pm 1,3$ & $3,4^{\mathrm{ab}} \pm 8,1$ & $8,3^{\mathrm{a}} \pm 5,3$ & $2,2^{b} \pm 5,5$ \\
\hline
\end{tabular}

A análise estatística foi realizada distintamente entre as amostras de arroz cru e arroz cozido devido ao fato de que para o processo de cocção das amostras, foram adicionados $\mathrm{NaCl}$, óleo de soja e água nestas, alterando assim sua composição, o que tornaria pouco adequada a comparação.

No arroz cru os valores de umidade não apresentaram diferença significativa entre as diferentes marcas e de mesmo tipo (branco, parboilizado e integral), porém a amostra número 06 de arroz parboilizado apresentou-se significativamente diferente, com $9,8 \mathrm{~g} 100 \mathrm{~g}^{-1}$ de umidade, demonstrando variações no processo de secagem após a parboilização. A amostra de arroz branco identificada com

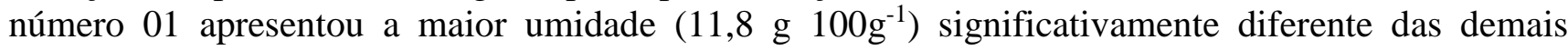
( $\mathrm{p}<0,05)$, mas ainda aceitável para comercialização. Os teores de umidade em arroz cozido também não diferiram significativamente quanto às marcas, mas pode-se observar que as amostras de arroz integral (07, 08 e 09) apresentaram os menores valores $\left(57,2,59,4\right.$ e 58,9 g 100 $\mathrm{g}^{-1}$, respectivamente), demostrando que este tipo de arroz tem menor absorção de água durante o processo de cocção devido a presença de farelo. De acordo com a TACO - Tabela Brasileira de Composição de Alimentos,

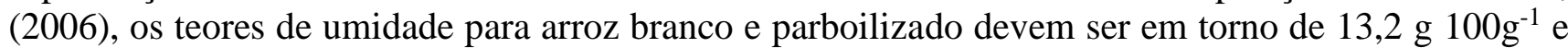

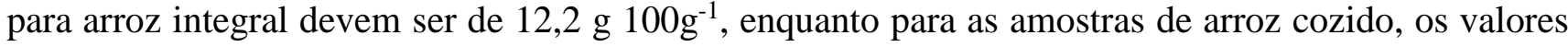


devem ser em torno de 69,1, 68,7 e 70,1 g $100 \mathrm{~g}^{-1}$ para arroz branco, parboilizado e integral cozido, respectivamente, estando os valores encontrados neste trabalho, ligeiramente abaixo do estipulado, possivelmente para o arroz integral maiores teores de água devessem ser empregados durante o tratamento.

Para os teores de cinzas apenas a amostra 09 apresentou diferença significativa das demais

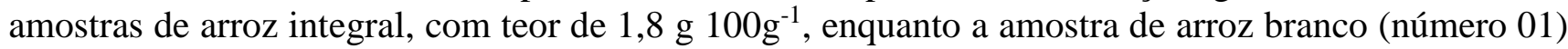

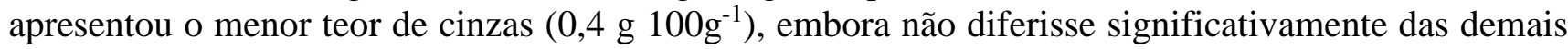
amostras de mesmo tipo. Estes resultados estão de acordo com os mencionados em outros trabalhos que avaliaram composição centesimal de arroz (DORS, 2006). As amostras de arroz cozido obtiveram valores de cinzas relativamente maiores que as de arroz cru, visto que nelas houve a adição de $\mathrm{NaCl}$, para simulação do cozimento doméstico.

Os teores de proteína nas amostras de arroz cru não diferiram significativamente entre os tipos e

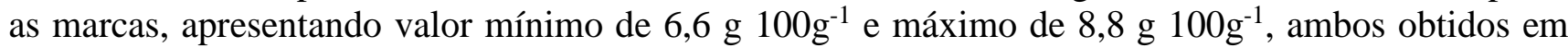
amostras de arroz parboilizado. O mesmo ocorreu nas amostras de arroz cozido, que se apresentaram com teores mínimos de 6,3 g 100g-1 (arroz integral) e máximo de 9,0 g 100g-1 (arroz parboilizado).

A fração de extrato etéreo foi a que apresentou a maior variação de resultados tanto para as amostras cruas, quanto para as amostras com cocção. A amostra de arroz branco identificada como

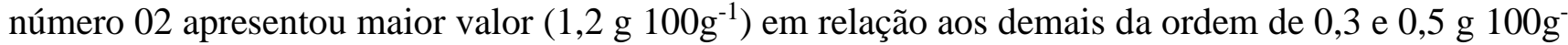
1 . Os maiores teores foram apresentados nas amostras de arroz integral, onde o valor mínimo foi de

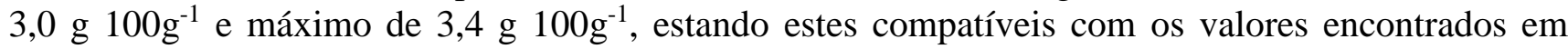
estudos anteriores (Dors, 2010). As amostras de arroz com cocção tiveram acréscimo de óleo de soja para o seu preparo, e por isso, houve maior variação do teor de lipídeos, encontrando-se também valores relativamente maiores quando comparadas amostras de arroz branco e parboilizado, e ao contrário dos minerais o teor de lipídeos incorporado no arroz integral cozido foi menor em todas as amostras.

Os resultados das análises de digesbilidade in vitro estão expressos na Figura 01:

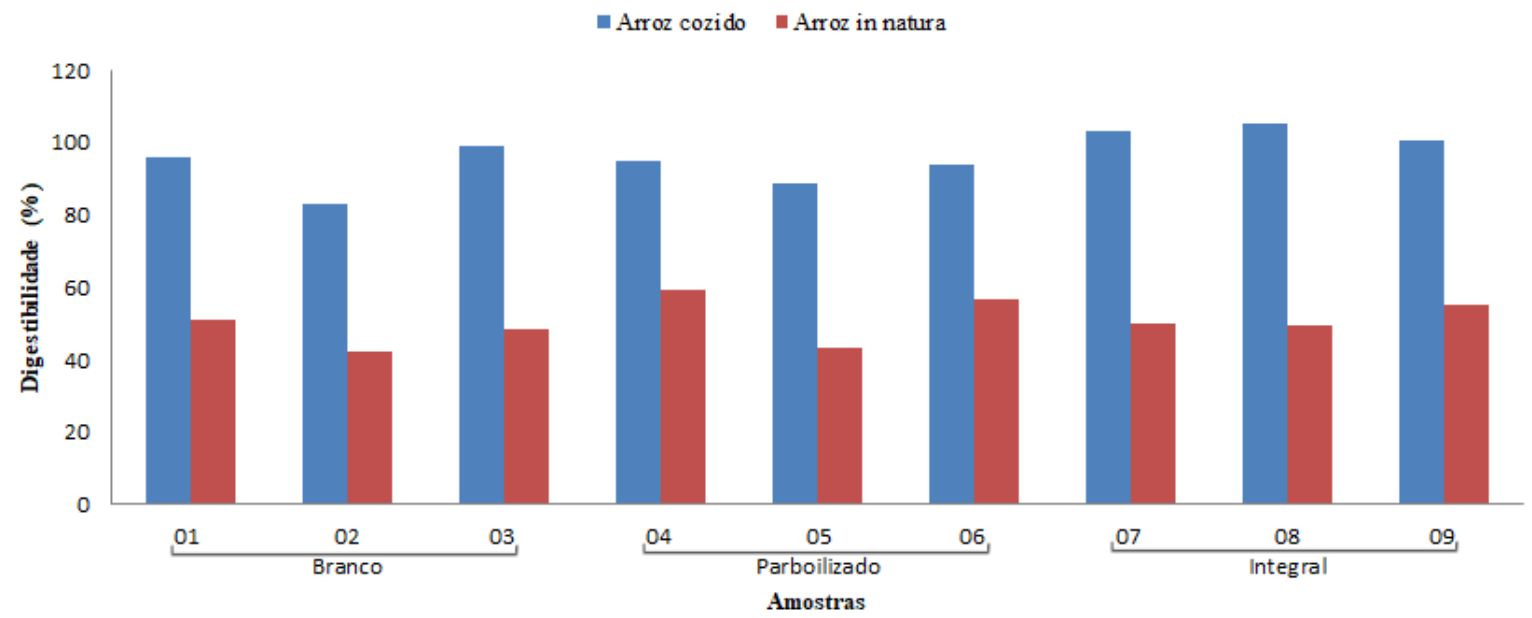

Figura 01: Estimativa da digestibilidade in vitro de amostras de arroz cru e arroz com cocção.

Os teores de digestibilidade de proteína in vitro para o arroz cru tiveram variação de 42,2 a 
$59,2 \%$ enquanto que as amostras de arroz após cocção obtiveram valores entre 83 e $105 \%$. Os menores valores para as amostras de arroz cru foram quantificados nas amostras de arroz branco $(42,2,48,5$ e $51,3 \%)$ enquanto que as taxas mais altas foram observadas no arroz parboilizado, (43,5 a $59,2 \%)$. Estudos determinando digestibilidade in vitro de proteínas em arroz após cocção são escassos, entretanto estima-se que esta apresente valores superiores quando comparado com a amostra crua, pois o processo de gelatinização do amido durante a cocção e conseqüente entrada de água entre as cadeias facilita a ação das enzimas proteolíticas aumentado a digestilidade protéica. A digestibilidade in vitro do amido também tem essa característica, sendo que já foram reportados aumento de 35 a $40 \%$ na disgestibilidade do amido após processos térmicos como cozimento e autoclavagem por exemplo (ROOPA, PREMAVALLI, 2008).

\section{CONCLUSÃO}

A caracterização química das amostras cruas mostrou que estas apresentaram variação na composição de acordo com o beneficiamento. Os teores que mais variaram foram de cinzas e lipídeos com valores médios de 1,63 e $3,2 \mathrm{~g} .100 \mathrm{~g}^{-1}$, respectivamente, para o arroz integral. Os maiores teores de umidade e proteína foram obtidos nas amostras de arroz branco. O cozimento provocou um aumento médio de $50 \%$ na digestibilidade e significativas variações na composição centesimal quando comparadas ao arroz cru, relacionadas com os teores de água, $\mathrm{NaCl}$ e óleo de soja absorvidos durante o tratamento térmico.

\section{REFERÊNCIAS}

AOAC - Association of Official Analytical Chemists. Official methods of analysis of the AOAC international. $15^{\circ}$ ed., Arlington: AOAC, 1990. p. 1185-1213, 2000.

BRASIL - Ministério da Agricultura, Pecuária e Abastecimento. Instrução Normativa n ${ }^{\circ} 6$ de 16 de fevereiro de 2009. Regulamento Técnico do Arroz. Disponível em:<http://extranet.agricultura.gov.br/sislegisconsulta/consultarLegislacao.do?operacao=visualizar\&i d=19480 >. Acesso em: 1 out. 2015.

CINTRA, R. M. G. C.; MAGALHÃES, C. O.; GARCIA, R. R.; MELLO, R.; PADILHA, A.; KUSAI, C.; CAETANO, L. Avaliação da qualidade da proteína de arroz e feijão e de dieta da região sudeste do Brasil. Alim. Nutr., v. 18, n. 3, p. 283-289, jul./set. 2007.

DORS, G. C. Arroz parboilizado: situação mcotoxicológica e suas relações com as condições de parboilização. Dissertação (Mestrado). Programa de Pós-Graduação em Engenharia e Ciência de Alimentos. Universidade Federal do Rio Grande. 2006.

DORS, G. C. Uso de fungicida no cultivo de arroz irrigado e seus efeitos na composição físicoquimica, bioquimica e micotoxicológica dos derivados do grão. Tese (Doutorado). Programa de Pós Graduação em Engenharia e Ciência de Alimentos. Universidade Federal do Rio Grande. 2010.

LOWRY, O. H.; ROSEBROUGH, N. J.; FARR, A. L. et al. Protein measurement with the Folin 
Phenol reagent. J. Biol. Chem., v. 193, p. 265-275, 1951.

MARCHINI , J. S.; RODRIGUES, M. M. P.; CUNHA, S. F. C.; FAUSTO, M. A.; VANNUCCHII, H.; OLIVEIRA, J. E. D. Cálculos das recomendações de ingestão protéica: aplicação à pré-escolar, escolar e adulto utilizando alimentos brasileiros. Rev. Saúde Públ., São Paulo, v. 28, p. 146-152, 1994.

ROOPA, S.; PREMAVALLI, K. S. Effect of processing on starch fractions in different varieties of finger millet. Food Chem., v. 106, p. 875 - 882, 2008.

SGARBIERI, V. C. Proteínas em alimentos Proteicos: Propriedades, coesadações, modificações. São Paulo, SP: Livraria Varela, 1996, 517p.

STORCK, C. R.; Variação na composição química em grãos de arroz submetidos a diferentes beneficiamentos. 108 f. Dissertação (Mestrado). Programa de Pós Graduação em Ciência e Tecnologia de Alimentos da Universidade Federal de Santa Maria, 2004.

TACO - Tabela brasileira de composição de alimentos / NEPA-UNICAMP.Versão II. 2. ed. Campinas, SP: NEPA-UNICAMP, 2006. 113p.

VIEIRA, N. R. A.; CARVALHO, J. L. V. Qualidade Tecnológica do Arroz. In: Vieria, N.R.A.; Santos, A.B.; Sant'ana, E.P.A. A Cultura de Arroz no Brasil. Embrapa Arroz e Feijão. Goiás, 1999.

ZHOU, Z. Composition and functional properties of rice. Int. J. Food Sci. Tech., v. 37, p. 849868, 2002. 